Emich, B., Dijk, L. van, Monteiro, S.P., Gier, J.J. de. A study comparing the effectiveness of three warning labels on the package of driving-impairing medicines. International Journal of

\begin{tabular}{|l|l|}
\hline $\begin{array}{l}\text { Postprint } \\
\text { Version }\end{array}$ & 1.0 \\
\hline Journal website & $\underline{\text { http://link.springer.com/article/10.1007\%2Fs11096-014-0010-2 }}$ \\
\hline Pubmed link & $\underline{\text { http://www.ncbi.nlm.nih.gov/pubmed/25204257 }}$ \\
\hline DOI & $10.1007 /$ s11096-014-0010-2 \\
\hline
\end{tabular}

This is a NIVEL certified Post Print, more info at http://www.nivel.eu

\title{
A study comparing the effectiveness of three warning labels on the package of driving-impairing medicines
}

\author{
BAS EMICH $^{1}$, Liset VAn DiJK ${ }^{2}$, Susana P. MONTEIRO ${ }^{1}$ AND JOHAN J. DE GIER ${ }^{1}$ \\ (1) University of Groningen, Groningen, The Netherlands \\ (2) NIVEL, Netherlands Institute for Health Services Research, Utrecht, The Netherlands
}

\begin{abstract}
Background: Several medicines are known to potentially impair patients' driving fitness. Appropriate communication towards patients about this risk can be supported by the use of package warning labels. Objective: To compare the effectiveness of a standing practice yellow/black label—with written warning — with a newly developed rating model in communicating risk on driving-impairing medicines (DIMs). Furthermore, the added value of a side-text in the rating model was determined. Setting: Community pharmacies in the Netherlands. Method In a crosssectional study, patients with a first dispensing of a DIM were asked by their community pharmacists $(n=38)$ to fill out a written questionnaire to compare each of the three warning labels. A 2 [yellow/black label vs. rating model (pair 1) and rating model with side-text vs. rating model without side-text (pair 2)] $\times 3$ [category of driving-impairment: I = minor risk, II = moderate risk, III = severe risk] design was used. The category of driving-impairment varied per respondent, depending on the DIM the patient collected. Main outcome measure: (1) estimated level of driving risk valued by patients (2) intention to change driving behaviour after seeing the warning label. Results: An estimated number of 992 patients were approached. As 298 questionnaires were analysed, the net response rate was $30 \%$. With the yellow/black label, respondents considered DIMs of all three categories of drivingimpairment to equally impair driving fitness, while with the rating model the estimated risk was higher when the category referred to a higher level of drivingimpairment. Addition of a side-text to the rating model resulted in a significantly higher estimated level of driving risk and a significant increase in intention to change driving behaviour. Only $8.0 \%$ of the patients using a category III DIM estimated the level of driving risk correctly when seeing the yellow/black label, while this was 26.7 $\%$ for the rating model and $43.0 \%$ for the rating model with side-text. Conclusion: The yellow/black label, which is standing practice in the Netherlands, is less effective in terms of estimated risk and intention to change driving behaviour, compared to a newly developed rating model. This model is even more effective
\end{abstract}


Emich, B., Dijk, L. van, Monteiro, S.P., Gier, J.J. de. A study comparing the effectiveness of three warning labels on the package of driving-impairing medicines. International Journal of Clinical Pharmacy: 2014, 36(6), 1152-1159

when a side-text is added. Implementation of the rating model in clinical practice should be considered.

\section{IMPACTS OF FINDINGS ON PRACTICE}

- The use of warning labels on the package of driving-impairing medicines (DIMs) in the Netherlands can be improved. A newly developed pictogram seems to be more effective in terms of estimated risk and intention to change driving behaviour than the yellow/black label.

- Proper warning labels can be useful as a support tool to provide tailor-made information to patients consuming DIMs. Both patients and pharmacists will benefit.

\section{INTRODUCTION}

More than seven hundred medicines are known to potentially impair patients' driving fitness (referred to as DIMs, driving-impairing medicines) [1]. The main groups that have been identified as such include benzodiazepines, opioid analgesics, antidepressants and first-generation antihistamines [2-8]. Most recent categorization system is a system developed within the Driving under the Influence of Drugs, Alcohol and Medicines (DRUID) project [9], in which nearly all DIMs available in the European Union have been classified into three categories of driving-impairment (referred to as categories). Category I DIMs have minor influence on driving fitness. For category II and III DIMs this influence is moderate and severe, respectively [1]. Appropriate communication about the potential risk of these DIMs is essential towards patients who are willing to participate in traffic. Risk communication is important for effective decision making in healthcare settings [10-14] as it stimulates patients to weigh the benefits and risks of a treatment choice or behavioural change $[11,15]$. As such, risk communication contributes to informed patient consent [13, 14]. The community pharmacy is the most suitable place to communicate this risk, as it usually is the last opportunity for patients to be informed by healthcare professionals before indeed starting treatment. Furthermore, in the past few years pharmacists are expected to play a more central role in providing information to patients at time of dispensing [16]. Although communication on risk of driving under the influence of DIMs is relevant for patients, this issue will be part of a counselling practice in which concerns, expectations and beliefs about their medicines are to be discussed. It is unclear how more emphasis on DIMs will affect pharmacy practice if pharmacists have to comply with time constrains and increased patient centeredness. In the Netherlands, a warning label is used on the package of DIMs since 1973 (referred to as the yellow/black label). This yellow label contains a warning in black writing (Fig. 1). It does not make any distinction between the three categories of driving-impairment. Furthermore, there is no visual expression by familiar symbols as in pictograms, while patients' understanding of risk has been found to increase by visual display of information $[13,17]$. Moreover, previous studies showed that the majority of patients did not change their intention to drive a car while using a DIM that was delivered with the yellow/black label $[18,19]$. As such, there is room for improvement concerning risk communication on the package of DIMs in the Netherlands. 
Emich, B., Dijk, L. van, Monteiro, S.P., Gier, J.J. de. A study comparing the effectiveness of three warning labels on the package of driving-impairing medicines. International Journal of Clinical Pharmacy: 2014, 36(6), 1152-1159

\section{[FIGURE 1]}

\section{Pictograms and DIMs}

The European Union suggested in 2005 to introduce a harmonized pictogram in all Member States. The United States Pharmacopoeia (USP) describes pharmaceutical pictograms as "standardized graphic images that help convey medication instructions, precautions, and/or warnings to patients and consumers” [20]. A new model (Fig. 2) was developed within the DRUID project (referred to as the rating model) $[8,21]$. This pictogram reflects all possible levels of risk in a horizontal bar of four boxes: 0 (no impairment; green), 1 (minor risk; yellow), 2 (moderate risk; orange) and 3 (severe risk; red), thus clarifying the relevance of the different levels of risk. A triangle with a black car inside is shown in the box which represents the category of the dispensed DIM. In order to provide action-oriented guidance to patients, a side-text can be added to the rating model (Fig. 2). The side-text used in this study is derived from the French model for indicating DIMs and adjusted by DRUID partners $[1,21,22]$.

\section{[FIGURE 2]}

Studies on the use of warning labels on the package of DIMs in other countries such as Spain, Australia and France showed that it can enhance patients' understanding and influence patients to reduce their driving frequency [23, 24]. Furthermore, a previous study of our research team showed that the DRUID pictogram is understood better by respondents than the current French pictogram [21]. However, the DRUID pictogram has not yet been compared to current practice in the Netherlands: the yellow/black label.

\section{Aim of the study}

The aim of this study was to evaluate and compare the effectiveness of the yellow/black label and the DRUID rating model in communicating risk on DIMs, to patients initiating the use of a DIM. Furthermore, the added value of a side-text in the rating model was determined. Effectiveness was aimed to be determined in terms of estimated level of driving risk and intention to change driving behaviour.

\section{Ethical approval}

In this study patients were only asked for their interpretation of warning labels in a general context. Therefore no approval of the medical ethics committee is needed in the Netherlands. All community pharmacists and patients participated voluntarily and anonymously and were well-informed by the research team beforehand.

\section{METHOD}

\section{Design}

In this cross-sectional study, patients with a first dispensing of any DIM classified in category I, II or III were asked to fill out a written questionnaire by their community pharmacist during a 7-week period. All community pharmacists in the Netherlands received an online invitation to participate in the study. Conditions for participation were: (1) using the yellow/black label on the package of DIMs of all categories, and (2) ability to select patients with a first dispensing of a DIM from their pharmacy dispensing software. 
Emich, B., Dijk, L. van, Monteiro, S.P., Gier, J.J. de. A study comparing the effectiveness of three warning labels on the package of driving-impairing medicines. International Journal of Clinical Pharmacy: 2014, 36(6), 1152-1159

Patient inclusion criteria were: (1) possession of a driving license, and (2) driving a car at least once in the previous 6 months. The pharmacist checked these criteria with the patient and, as an extra check, these questions were also asked in the questionnaire. Patients were asked to return the questionnaire to the research team within 2 weeks. After the study period, about half of the participating pharmacists reported the number of questionnaires they distributed to patients. Their answers were used to estimate the net response rate and the total number of distributed questionnaires.

\section{Questionnaire}

Different versions of the questionnaire were made for category I, II and III DIMs. The questionnaire started with questions about socio-demographic characteristics. Next, respondents were asked identical questions for all three warning labels included in the study, corresponding to the category of the dispensed DIM. As patients were confronted with the yellow/black label on their medicine package in the community pharmacy (as standing practice), it was considered to be logical to pose questions on this label first in the row of three. Questions on the other two labels (rating model with and without side-text) were alternated to avoid answering bias caused by the order in which the warning labels were posed, resulting in two different versions of the questionnaire for each category of driving-impairment.

\section{Estimated level of driving risk}

Respondents were asked "How dangerous would you value driving a car if this warning label was affixed to your medicine box?”. A 4-point scale was used to estimate this risk ( 1 = harmless to 4 = very dangerous). Answers were coupled with categories to determine the number of respondents who estimated the risk correctly: category I: 2 = low danger; category II: 3 = dangerous; category III: 4 = very dangerous. Option 1 = harmless was not coupled with one of the categories since this answer represents medicines without any influence on driving fitness.

\section{Intention to change driving behaviour}

To express respondents' intention to change their driving behaviour, patients were asked how likely they would change their driving behaviour if the warning label was affixed to their medicine box. Answers ranged from 1 = very unlikely to 5 = very likely. Furthermore, respondents were asked how often they would drive after dispensing of the DIM. Answers ranged from $1=$ driving equally to $5=$ not anymore.

\section{Socio-demographic characteristics}

Gender, age and education level were assessed. The different education levels were reduced to three levels: low (no education, primary school, lower secondary education, lower vocational education), intermediate (intermediate secondary education, intermediate vocational education) and high (higher vocational education, university degree).

\section{Analysis}

A 2 [yellow/black label vs. rating model (pair 1) and rating model with side-text vs. rating model without side-text (pair 2)] $\times 3$ [category of driving-impairment: I, II and III] design was used for conducting analysis. Respondents who failed to answer a question or provided more than one answer were excluded from the analyses for that 
Emich, B., Dijk, L. van, Monteiro, S.P., Gier, J.J. de. A study comparing the effectiveness of three warning labels on the package of driving-impairing medicines. International Journal of Clinical Pharmacy: 2014, 36(6), 1152-1159

question. To assess differences in the composition of the patient population for the different categories of DIMs in terms of gender, age and educational level, Chi square tests and one-way ANOVA analyses were used. To determine differences between the warning labels on estimated risk and intention to change driving behaviour, paired t tests were conducted. Additionally, one-way ANOVA analyses (with post hoc Bonferroni tests) were performed to determine the difference between categories on these items, with estimated risk and intention to change driving behaviour as dependent variables and the categories as factors. $\mathrm{P}$ values lower than 0.05 were considered to be statistically significant.

\section{RESULTS}

Thirty-eight community pharmacies were enrolled in the study. A total of 321 patients returned the questionnaire, 23 of whom were excluded as they did not possess a driving license $(n=19)$ or did not participate in traffic recently $(n=4)$. Of the analysed questionnaires, 49 (16.4\%) concerned category I DIMs, 110 (36.9\%) category II DIMs and 139 (46.6 \%) category III DIMs. Twenty-three pharmacies reported the number of distributed questionnaires after the data collection was finished. After correction for the non-responding pharmacies, the estimated number of distributed questionnaires was 992, resulting in a net response rate of $30 \%$. Respondents' characteristics are summarized in Table 1 . The study population included more women than men ( $\mathrm{n}=182$; $61.3 \%$ female) and the mean age was 53.6 $( \pm 15.0)$ years. Respondents in the different categories did not differ on gender and education level, but respondents who used a category I DIM were significantly younger compared to those who used a DIM within the two other categories.

\section{[TABLE 1$]$}

\section{Estimated level of driving risk}

With the yellow/black label, respondents estimated the level of driving risk about the same for all categories of DIMs ( $\mathrm{P}=0.50)$, while for the rating model this risk was significantly higher when the category of driving-impairment was more severe $(\mathrm{P}<$ 0.001 , Fig. 3a). Addition of side-text to the rating model resulted in significantly higher levels of estimated risk in all three categories, ranging from low danger $(\mathrm{P}=$ $0.03)$ to dangerous $(\mathrm{P}<0.001$, Fig. $3 \mathrm{~b})$.

\section{[FIGURE 3]}

Regardless of the warning label, most of the patients using a category I DIM estimated the potential risk correctly (ranging from 67.3 to $75.5 \%$ ). When seeing the yellow/black label, only $8.0 \%$ of the respondents using a category III DIM estimated this risk correctly, while this was $26.7 \%$ for the rating model and $43.0 \%$ for the rating model with side-text (Fig. 4).

\section{[FIGURE 4]}

As an alternative analysis patients using a category III DIM were considered to be right when they judged the driving risk as either $3=$ dangerous or $4=$ very dangerous. In that case $44.5 \%$ estimated the risk correctly with the yellow/black label, while these values were 80.0 and $67.4 \%$ for the rating model with and without side-text, respectively. 
Emich, B., Dijk, L. van, Monteiro, S.P., Gier, J.J. de. A study comparing the effectiveness of three warning labels on the package of driving-impairing medicines. International Journal of Clinical Pharmacy: 2014, 36(6), 1152-1159

\section{Intention to change driving behaviour (likelihood)}

Regardless of the warning label, respondents' intention to change driving behaviour is about the same for category II and III DIMs and is lower for minor risk DIMs. This difference between category I and higher risk DIMs is least obvious for the yellow/black label (Fig. 5a). Addition of side-text to the rating model resulted in a significantly higher intention to change driving behaviour in all three categories, ranging from neutral in category I $(\mathrm{P}=0.03)$ to likely in category II and III $(\mathrm{P}<$ 0.001, Fig. 5b).

\section{[FIGURE 5]}

\section{Intention to change driving behaviour (driving frequency)}

For each of the three warning labels, respondents' intention to reduce their driving frequency is significantly higher when the potential driving-impairment of the dispensed DIM is more severe $(\mathrm{P}<0.001)$, though for the yellow/black label this is least obvious (Fig. 6a). Addition of side-text to the rating model resulted in a significantly higher intention to reduce driving frequency, ranging from driving equally / slightly less often $(P=0.01)$ to nearly much less often $(P<0.001$, Fig. $6 b)$.

\section{[FIGURE 6]}

\section{DISCUSSION}

As the risk of driving under the influence of DIMs is considerable, proper risk communication is essential towards patients who are willing to participate in traffic. This communication can be supported by the use of warning labels on medicine boxes. This study compared the effectiveness of the yellow/black label as currently used in the Netherlands and a rating model (with and without a side-text) as proposed within the DRUID project. The yellow/black label does not seem to communicate risk on driving fitness in an adequate way, as stated before in other studies $[18,19]$. Moreover, the rating model turned out to be an appropriate alternative, especially when a side-text is added.

For the yellow/black label, patients estimated the level of driving risk to be equal for all categories of driving-impairment (category I, II and III), despite of the great differences in actual risk. Moreover, only $8.0 \%$ of the patients using a severe risk DIM estimated this risk correctly. Considering the rating model, on the other hand, the estimated risk was greater as the category of the DIM was more severe. Yet, if the rating model were to be introduced, addition of a side-text is recommendable, as it results in a significant increase of estimated risk and respondents' intention to change their driving behaviour. Moreover, of all three labels investigated, the number of respondents who estimated the risk of severe risk DIMs correctly is highest using this model (43.0\%).

Although the clear differences in estimated level of driving risk between the yellow/black label and the rating model without side-text, respondents' intention to change their driving behaviour did not differ that much. Possibly the combination of the yellow/black label and the information given to patients in the pharmacy at dispensing is sufficient to result in an intention to change behaviour, even without patients realizing the actual risk of the DIM. They may learn this risk from the rating model in the questionnaire while the intention to change driving behaviour is not 
Emich, B., Dijk, L. van, Monteiro, S.P., Gier, J.J. de. A study comparing the effectiveness of three warning labels on the package of driving-impairing medicines. International Journal of Clinical Pharmacy: 2014, 36(6), 1152-1159

influenced any further. When patients see the rating model with side-text, on the other hand, this intention is increased significantly, probably caused by the specific textual instruction which is lacking in the rating model without side-text: the combination of visual (pictogram) and written (side-text) information is known to help patients to assess pictograms better than the pictogram on its own [26, 27]. The effectiveness of the rating model has been investigated before by Monteiro et al. [21]. Similar to our study, the estimated risk with the rating model was found to be greater as the category of the DIM was more severe. However, contrary to our study, no added value of side-text was found. This may be caused by the fact that almost half of the participants in the Monteiro study had a university degree. Highly educated patients might already interpret the rating model correctly without the need of side-text [28]. In our study the education level of respondents was more representative of the Dutch population. Moreover, contrary to the Monteiro study, our study was carried out among patients who were actually in the situation to make a decision changing their driving behaviour, namely those with a first dispensing of a DIM.

\section{Strengths and limitations}

A strength of this study is that it is performed in the actual target population for the warning labels and that the category of driving-impairment is taken into consideration, increasing the study's external validity. Furthermore, as identical questions were asked about each of the three warning labels, respondents were able to make a direct comparison between the different labels.

A limitation of the study is the small sample size $(\mathrm{N}=298)$, although common in this type of research [29]. Especially the number of respondents using a minor risk DIM $(n=49)$ was relatively low. This, however, reflects clinical practice: the number of users in category II and especially category III is higher than in category I [30]. Another limitation is the fact that the labels as printed in the questionnaires were slightly larger in size compared to how they are meant to be used in practice. As a result, the added value of text (yellow/black label and rating model with side-text) might have been overestimated, especially in patients with visual impairments. The questionnaire in this study has not been validated. However, it can be seen as reliable, as it is derived from the Monteiro study: that questionnaire was developed by NIVEL in corporation with representatives of relevant parties in the field [21]. Usability of the newly developed pictogram as additional information to written patient information leaflets could not be tested, resulting in a limitation when deciding on replacing warning labels in pharmacy practice based on our results.

\section{Impacts on practice}

Warning labels can enhance patients' understanding and can influence patients to reduce their driving frequency $[21,23,24]$. As such, warning labels should serve as support tools to provide tailor-made information to the patient in the community pharmacy, in which the risks (driving-impairment), benefits (cure) and patients' wishes are weighed $[11,15]$. The impact of these labels should be seen as a part of the whole process of reaching informed patient consent. Furthermore, not only patients will benefit: pictograms can help pharmacists in providing proper information towards patients as well, especially when it is supported by information integrated in the pharmacy dispensing software [25]. Our study emphasizes the need 
Emich, B., Dijk, L. van, Monteiro, S.P., Gier, J.J. de. A study comparing the effectiveness of three warning labels on the package of driving-impairing medicines. International Journal of Clinical Pharmacy: 2014, 36(6), 1152-1159

for proper printed materials to inform patients, but also that such labels should be used in the dispensing process as a whole.

\section{Future research}

In our study patients were provided with information in their community pharmacy with the yellow/black label attached to their medicine box, while they had never been confronted with the two rating models before. In future research different patients should be confronted with different labels, while receiving information as usual. Prior explanation of the intended meanings of warning labels is known to have high impact on comprehension and recall [27, 31]. Furthermore, future research should focus on the effectiveness of the DRUID rating model in other countries, to serve as scientific basis for the potential introduction at European level. Finally, the usability of patient information leaflets with various pictograms covering one or more warning issues should be explored in comparison with written information without pictograms.

\section{CONCLUSION}

The yellow/black label as currently used in the Netherlands does not support patients judging the danger of driving under the influence of DIMs in an adequate way, especially for severe risk medicines. This suggests the need for a new pictorial system in the Netherlands. The DRUID rating model can be seen as an appropriate alternative, especially when a side-text is added.

\section{Acknowledgments}

The authors thank all patients and pharmacy teams involved.

\section{Funding}

No external funding was received to conduct this study.

\section{Conflicts of interest}

The authors do not declare any conflict of interest.

\section{REFERENCES}

1. Ravera S, Monteiro SP, de Gier JJ, van der Linden T, Gómez-Talegón T, Álvarez FJ, et al. A European approach to categorizing medicines for fitness to drive: outcomes of the DRUID project. Br J Clin Pharmacol. 2012;74(6):920-31.

2. Corsenac P, Lagarde E, Gadegbeku B, Delorme B, Tricotel A, Castot A, et al. Road traffic crashes and prescribed methadone and buprenorphine: a French registry-based casecontrol study. Drug Alcohol Depend. 2012;123(1-3):91-7.

3. Engeland A, Skurtveit S, Mørland J. Risk of road traffic accidents associated with the prescription of drugs: a registry-based cohort study. Ann Epidemiol. 2007;17(8):597-602.

4. Kelly E, Darke S, Ross J. A review of drug use and driving: epidemiology, impairment, risk factors and risk perceptions. Drug Alcohol Rev. 2004;23(3):319-44.

5. Orriols L, Queinec R, Philip P, Gadegbeku B, Delorme B, Moore N, et al. Risk of injurious road traffic crash after prescription of antidepressants. J Clin Psychiatry. 2012;73(8):108894.

6. Verster JC, Volkerts ER. Antihistamines and driving ability: evidence from on-the-road driving studies during normal traffic. Ann Allergy Asthma Immunol. 2004;92(3):294-303.

7. Verster JC, Veldhuijzen DS, Patat A, Olivier B, Volkerts ER. Hypnotics and driving safety: meta-analyses of randomized controlled trials applying the on-the-road driving test. Curr Drug Saf. 2006;1(1):63-71. 
Emich, B., Dijk, L. van, Monteiro, S.P., Gier, J.J. de. A study comparing the effectiveness of three warning labels on the package of driving-impairing medicines. International Journal of Clinical Pharmacy: 2014, 36(6), 1152-1159

8. Meesmann U, Boets S, Monteiro SP, de Gier JJ, Fierro I, Álvarez FJ. Main DRUID results to be communicated to different target groups (WP7). 2011. http://www.druid-project.eu/ Druid/EN/deliverales-list/downloads/Deliverable 73 2.pdf? $\quad$ blob=publicationFile\&v=1. Accessed 21 June 2014.

9. DRUID (Driving under the influence of drugs, alcohol and medicines) project. http://www. druid-project.eu. Accessed 4 April 2014.

10. Davis RE, Dolan G, Thomas S, Atwell C, Mead D, Nehammer S, et al. Exploring doctor and patient views about risk communication and shared decision-making in the consultation. Health Expect. 2003;6(3):198-207.

11. Edwards A, Elwyn G. How should effectiveness of risk communication to aid patients' decisions be judged?: a review of the literature. Med Decis Making. 1999;19(4):428-34.

12. Edwards A, Elwyn G, Hood K, Robling M, Atwell C, Holmes-Rovner M, et al. The development of COMRADE-a patient-based outcome measure to evaluate the effectiveness of risk communication and treatment decision making in consultations. Patient Educ Couns. 2003;50(3):311-22.

13. Paling J. Strategies to help patients understand risks. BMJ. 2003;327(7417):745-8.

14. Thomson R, Edwards A, Grey J. Risk communication in the clinical consultation. Clin Med. 2005;5(5):465-9.

15. Edwards A, Hood K, Matthews E, Russell D, Russell I, Barker J, et al. The effectiveness of one-to-one risk-communication interventions in health care: a systematic review. Med Decis Making. 2000;20(3):290-7.

16. Wheeler A, Crump K, Lee M, Li L, Patel A, Yang R, Zhao J, Jensen M, et al. Collaborative prescribing: a qualitative exploration of a role for pharmacists in mental health. Res Soc Adm Pharm. 2012;8(38):179-92.

17. Hill LH, Roslan MR. Using visual concept mapping to communicate medication information to chronic disease patients with low literacy: a preliminary study. Paper presented at first international conference on concept mapping; September 14-17, 2004; Navarra, Spain.

18. Stout QF, de Gier JJ. Effect van de geel-zwarte rijvaardigheidssticker op geneesmiddelen [Effect of the yellow-black warning label for driving on drugs; article in Dutch]. Pharmaceutisch Weekblad. 1982;117:449-52.

19. Veldhuijzen DS, van Wijck AJ, Verster JC, Kalkman CJ, Kenemans JL, Olivier B, Volkerts ER. The impact of chronic pain patients' psychotropic drug knowledge and warning labels on the decision whether to drive a car or not. Traffic Inj Prev. 2006;7(4):360-4.

20. USP (United States Pharmacopoeia), 2014. http://www.usp.org/usp-healthcareprofessionals/related-topics-resources/usp-pictograms. Accessed 4 April 2014.

21. Monteiro SP, Huiskes R, van Dijk L, van Weert JCM, de Gier JJ. How effective are pictograms in communicating risk about driving-impairing medicines? Traffic Inj Prev. 2013;14(3):299-308.

22. ANSM (Agence nationale de sécurité du médicament et des produits de santé). Medicinal products and driving. 2009. http://ansm.sante.fr/var/ansm site/storage/original/ application/e5f2e48d5344bcfef6ca865ac63e7c3d.pdf. Accessed 4 April 2014.

23. Fierro I, Gómez-Talegón T, Álvarez FJ. The Spanish pictogram on medicines and driving: the population's comprehension of and attitudes towards its use on medication packaging. Accid Anal Prev. 2013;50:1056-61.

24. Smyth T, Sheehan M, Siskind V, Mercier-Guyon C, Mallaret M. Consumer perceptions of medication warnings about driving: a comparison of French and Australian labels. Traffic Inj Prev. 2013;14(6):557-64.

25. Legrand SA, Boets S, Meesmann U, Verstraete AG. Medicines and driving: evaluation of training and software support for patient counselling by pharmacists. Int J Clin Pharm. 2012;34(4):633-4.

26. Dowse R, Ehlers M. Medicine labels incorporating pictograms: do they influence understanding and adherence? Patient Educ Couns. 2005;58(1):63-70.

27. Katz MG, Kripalani S, Weiss BD. Use of pictorial aids in medication instructions: a review of the literature. Am J Health Syst Pharm. 2006;63(23):2391-7.

28. Montagne M. Pharmaceutical pictograms: a model for development and testing for comprehension and utility. Res Soc Adm Pharm. 2013;9(5):609-20.CrossRef 
Emich, B., Dijk, L. van, Monteiro, S.P., Gier, J.J. de. A study comparing the effectiveness of three warning labels on the package of driving-impairing medicines. International Journal of Clinical Pharmacy: 2014, 36(6), 1152-1159

29. Stevens J. Applied multivariate statistics for the social sciences. London: Lawrence Erlbaum Associates; 2002.

30. SFK (Stichting Farmaceutische Kengetallen). Rijden onder invloed [Driving under influence; article in Dutch]. Pharmaceutisch Weekblad, 2009;144(26):18.

31. Wilby K, Marra CA, da Silva JH, Grubisic M, Harvard S, Lynd LD. Randomized controlled trial evaluating pictogram augmentation of HIV medication information. Ann Pharmacother. 2011;45(11):1378-83.

\section{FIGURES AND TABLES}

Table 1: Socio-demographic characteristics of respondents, per category $(\mathrm{N}=298)$

\begin{tabular}{|c|c|c|c|c|c|c|c|}
\hline & \multicolumn{2}{|c|}{$\begin{array}{l}\text { Category I (n = } \\
\text { 49) }\end{array}$} & \multicolumn{2}{|c|}{$\begin{array}{l}\text { Category II (n = } \\
\text { 110) }\end{array}$} & \multicolumn{2}{|c|}{$\begin{array}{l}\text { Category III (n = } \\
\text { 139) }\end{array}$} & \multirow{2}{*}{$\begin{array}{l}\mathbf{P} \\
\text { value }\end{array}$} \\
\hline & $\mathbf{n}$ & $\%$ & $\mathbf{n}$ & $\%$ & $\mathbf{n}$ & $\%$ & \\
\hline \multicolumn{8}{|l|}{ Gender } \\
\hline Male & 24 & 49.0 & 40 & 36.4 & 51 & 37.0 & $0.27^{\mathrm{a}}$ \\
\hline Female & 25 & 51.0 & 70 & 63.6 & 87 & 63.0 & - \\
\hline \multicolumn{8}{|l|}{ Age } \\
\hline Mean \pm SD & $48.2 \pm 17.1$ & & $55.2 \pm 14.6$ & & $54.2 \pm 14.2$ & & $0.02^{\mathrm{b}}$ \\
\hline Minimum & 21 & & 18 & & 19 & & - \\
\hline Maximum & 80 & & 87 & & 87 & & - \\
\hline \multicolumn{8}{|c|}{ Education level } \\
\hline Low & 12 & 24.5 & 42 & 38.2 & 49 & 35.3 & $0.45^{\mathrm{a}}$ \\
\hline Intermediate & 24 & 49.0 & 41 & 37.3 & 51 & 36.7 & - \\
\hline High & 13 & 26.5 & 27 & 24.5 & 39 & 28.1 & - \\
\hline
\end{tabular}

${ }^{\mathrm{a}} \mathrm{P}$ value calculated using Chi square test

${ }^{\mathrm{b}} \mathrm{P}$ value calculated using one-way ANOVA

Fig. 1 Yellow/black label as currently used in the Netherlands. Translation 'This medicine can impair your reaction time. (driving — using machines-playing on the street) Be careful in combination with alcohol!’. (Color figure online)

\section{DIT GENEESMIDDEL KAN HET REACTIEVERMOGEN VERMINDEREN. (autorijden - bedienen van machines - spelen op straat) Pas op met alcohol!}


Emich, B., Dijk, L. van, Monteiro, S.P., Gier, J.J. de. A study comparing the effectiveness of three warning labels on the package of driving-impairing medicines. International Journal of Clinical Pharmacy: 2014, 36(6), 1152-1159

Fig. 2 Rating model as developed within the DRUID project (left) and after the addition of a side-text (right) for the three different categories of driving-impairment. (Color figure online)

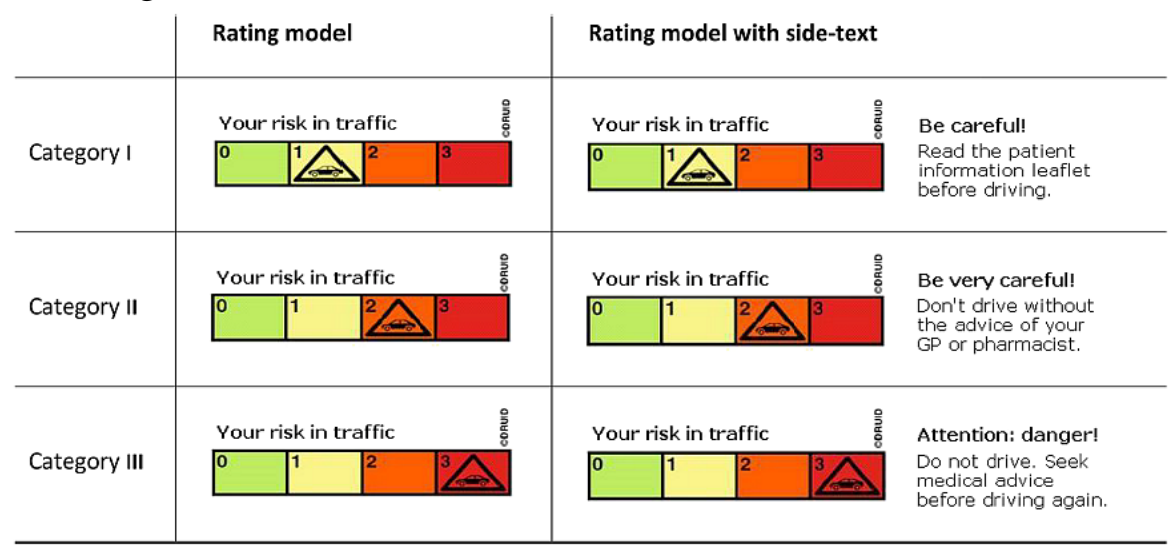

Fig. 3 Estimated level of driving risk: a pair 1 and b pair 2. Number of respondents: yellow/black label: category I, $\mathrm{n}=49$; II, $\mathrm{n}=106$; III, $\mathrm{n}=137$; rating model: $\mathrm{I}, \mathrm{n}=$ 49; II, $\mathrm{n}=103$; III, $\mathrm{n}=135$; rating model with side-text: I, $\mathrm{n}=49$; II, $\mathrm{n}=105$; III, $\mathrm{n}=$ 135. (Color figure online)
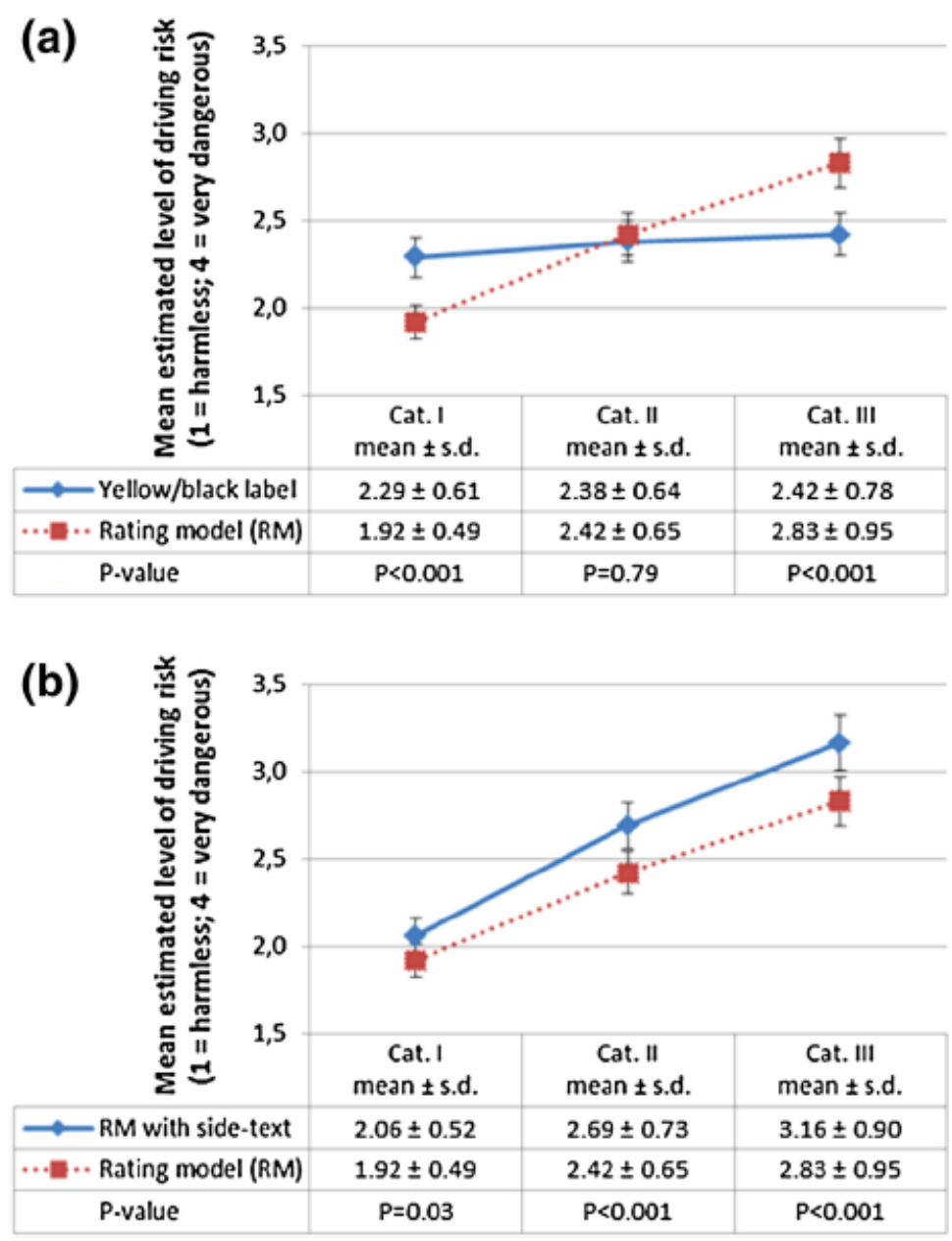
Emich, B., Dijk, L. van, Monteiro, S.P., Gier, J.J. de. A study comparing the effectiveness of three warning labels on the package of driving-impairing medicines. International Journal of Clinical Pharmacy: 2014, 36(6), 1152-1159

Fig. 4 The number of respondents who estimated the level of driving risk correctly. Categories of driving-impairment and estimated level of driving risk were coupled as follows: category I: 2 = low danger; category II: 3 = dangerous; category III: 4 = very dangerous. (Color figure online)

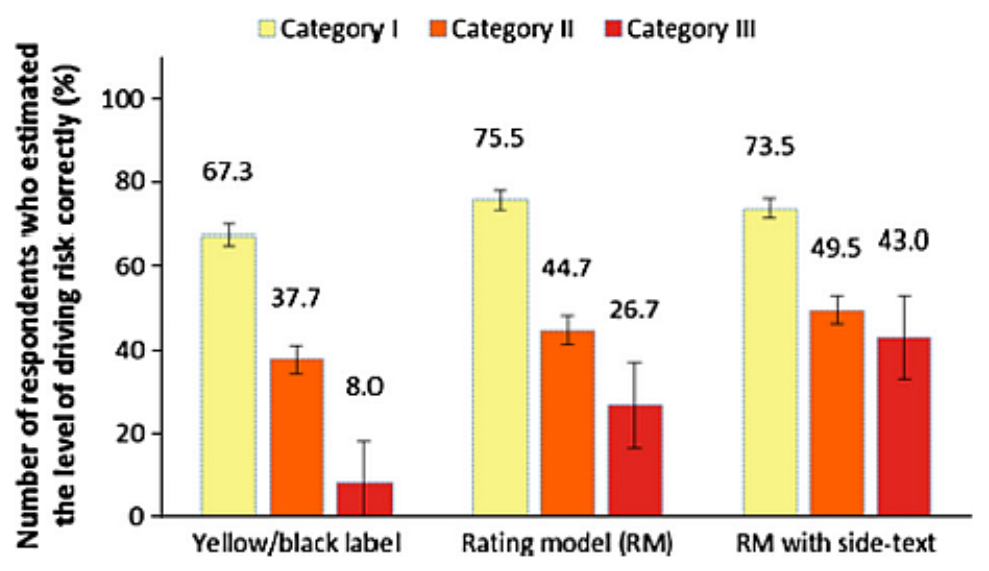

Fig. 5 Respondents' intention to change driving behaviour in terms of likelihood: a pair 1 and b pair 2. Number of respondents: yellow/ black label: category I, $n=49$; II, $\mathrm{n}=110$; III, $\mathrm{n}=139$; rating model: $\mathrm{I}, \mathrm{n}=49$; II, $\mathrm{n}=104$; III, $\mathrm{n}=137$; rating model with sidetext: I, $\mathrm{n}=49$; II, $\mathrm{n}=104$; III, $\mathrm{n}=136$. (Color figure online)
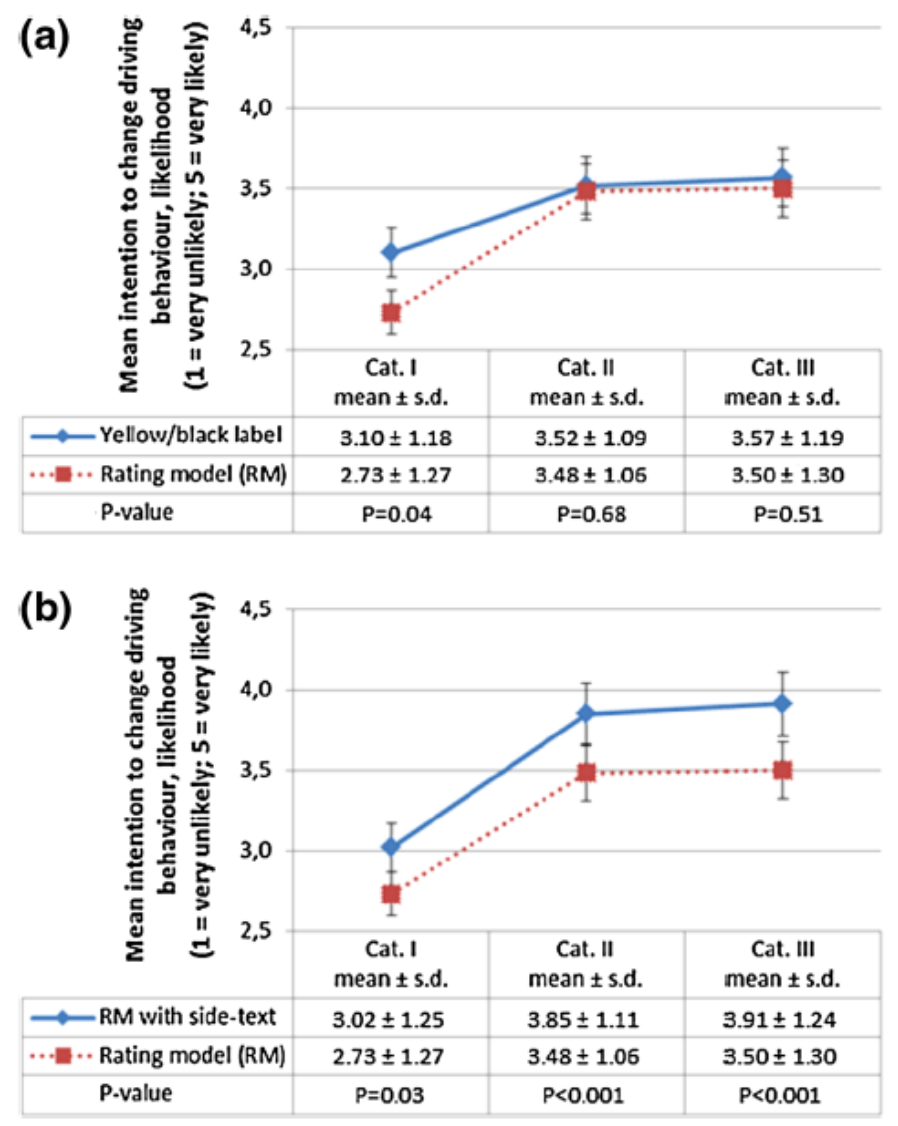
Emich, B., Dijk, L. van, Monteiro, S.P., Gier, J.J. de. A study comparing the effectiveness of three warning labels on the package of driving-impairing medicines. International Journal of Clinical Pharmacy: 2014, 36(6), 1152-1159

Fig. 6 Respondents' intention to change driving behaviour in terms of driving frequency: a pair 1 and b pair 2 . Number of respondents: yellow/black label: category I, $n=49$; II, $n=109$; III, $n=139$; rating model: I, $n=49$; II, $n=103$; III, $n$ $=137$; rating model with side-text: $\mathrm{I}, \mathrm{n}=49$; II, $\mathrm{n}=102$; III, $\mathrm{n}=135$. (Color figure online)
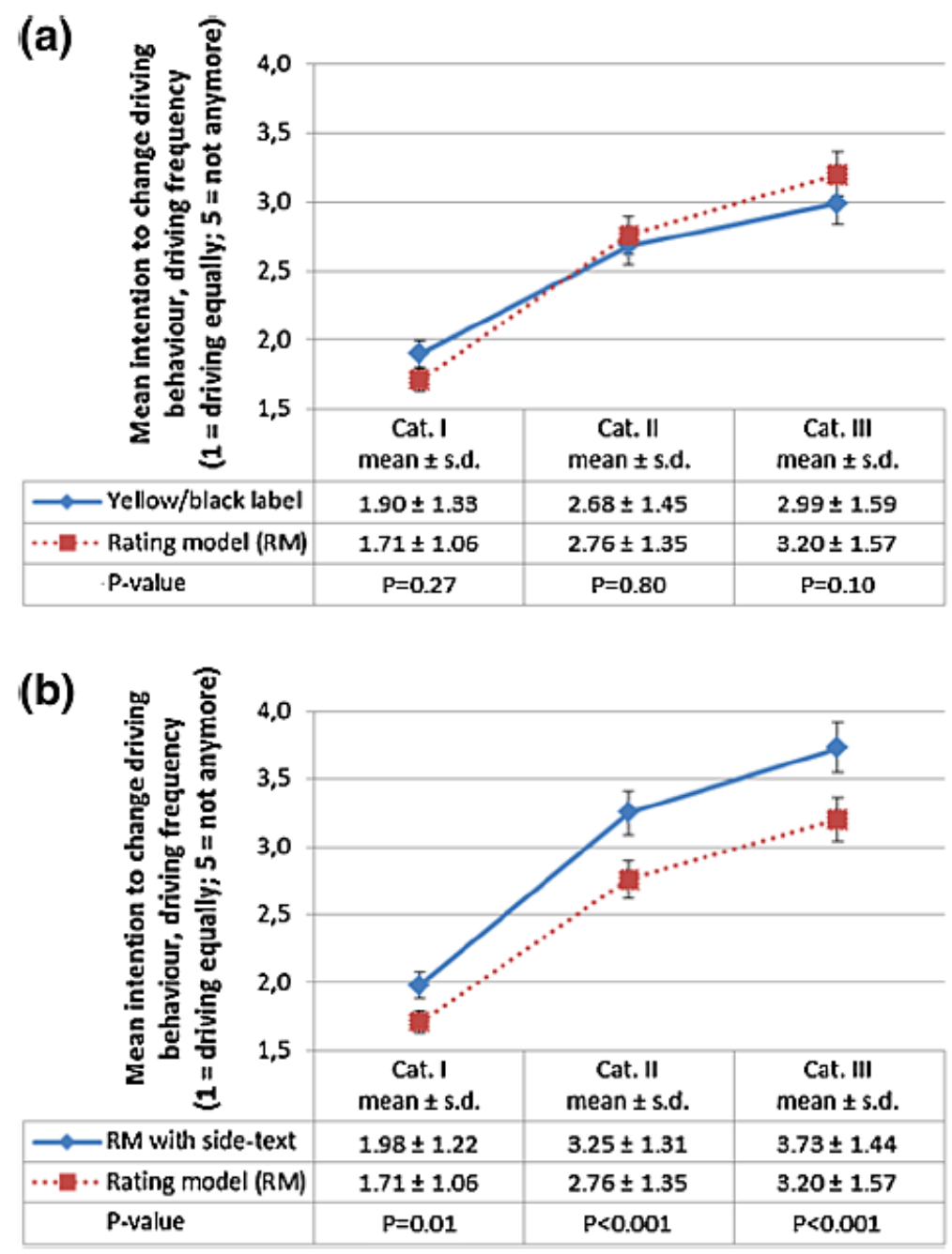